\title{
The Ambivalence
}

$\mathrm{I}_{\mathrm{E}}^{\mathrm{n}}$ n a recent essay titled "John Muir and the Roots of American Environmentalism" (in The Wealth of Nature, Oxford, 1993), environmental historian Donald Worster asks why it was North America - and not the East with its traditions of Buddhism and Confucianism, both of which might seem more likely starting points for environmental thinking-that gave rise to environmentalism. Reflecting on this, he suggests, perhaps somewhat surprisingly, that at least one reason was a strong tradition of liberal Protestantism, which espoused certain values - Worster identifies four: moral activism, ascetic discipline, egalitarian individualism and aesthetic spirituality-that provided a context for the development of environmental thinking. These, he suggests influenced the thinking of key figures such as Muir, and help to explain why environmentalism first took root in North America rather than in Europe or Asia.

Similarly, we may ask why restoration, understood in the strict sense as an attempt to return an ecosystem or a landscape to some previous (though dynamically conceived) condition, is also a distinctly American idea.

Clearly, there are a number of reasons for this. Perhaps the most obvious is that restoration emerged from environmentalism, and so shares with environmentalism deep roots in American culture and American experience.

More specifically, the "invention" of restoration, beginning with the work of turn-of-the-century figures such as Frederick Law Olmsted on the East Coast and Jens Jensen in Chicago, was clearly a response to the dramatic changes in the landscape that took place following European contact and settlement.

To this we might add the characteristically American cando attitude, the confidence of the Yankee inventor in the ability of humans to solve problems through enterprise and ingenuity.

Yet another factor was a distinctive set of ideas about the past, and an ambivalence about it that goes a long way toward explaining both the American "invention" of restoration and the ambivalence of environmentalists toward it.

From the beginning, Americans have been torn between two conflicting ideas about the past and our relationship with it.

The first of these is in fact another heritage from Protestantism-not the liberal Protestantism Worster discussed, but the conservative Protestantism that was brought to North America by the early Puritan and Calvinist pilgrims. This was a kind of primitivism, an idealization of the past, that took the form of what the religious historians Richard Hughes and C. Leonard Allen, in their book Illusions of Innocence: Protestant Primitivism in America, 1630-1875 (Chicago, 1988) have called "the myth of the restoration of first times." This is the idea that the ideal life lies in the past, and that redemption is achieved by stepping out of history in a deliberate attempt to recover the ideal "first time" of the foundation or the creation.

For the Puritans, of course, the ideal "first time" was represented by Eden, or by the primitive Church. But, as Hughes and Allen note, the idea was gradually extended to include the idea of primitive nature.

Clearly, it represents an important element in the sensibility that gave rise to what we now recognize as the beginnings of environmental thinking. And just as clearly it underlay the notion of restoration, which in effect takes the idea of restoration of first times literally, and seeks to reduce it to practice.

At the same time, this notion existed in tension with a very different idea of the past-the progressive idea that the past is hardly an ideal, but in fact something to escape from, as in fact the Puritans had felt themselves to be escaping from the Old World and its burden of history.

Today, as restoration takes shape as a practice, a discipline, and even the basis for an environmental paradigm, we are still working in the field of tension generated by these two different "takes" on the past, and this is reflected in the way we do restoration and also in the way we talk about it.

We undertake restoration projects eagerly enough, but at the same time we tend to reject the idea of restoration as a return to a former condition or an attempt to recover the past.

Rather than getting "bogged down in the past," we prefer to emphasize the progressive, forward-looking aspect of restoration.

It has a progressive aspect, certainly. Restoration projects exist in the present and are our contribution to the future. Yet it is worth keeping in mind that the conservative principle implicit in the term "re-storation" (from the Latin, meaning basically "to set up again") is an important and worthy one, and that the diversity and richness we are seeking to conserve do not exist in the present or future only, but are the result of the accumulation and conservation of what we inherit from the past.

William R. Jordan III 